\section{Contrast effects on the auditory evoked response and its relation to psychophysical judgments*}

\author{
MONTE BUCHSBAUM**, JULIAN SILVERMAN***, ROBERT I. HENKIN†, \\ and \\ ADOLF PFEFFERBAUM $+\dagger$ \\ National Institutes of Health, Bethesda, Maryland 20014
}

An auditory average evoked response (AER) procedure was used to search for a physiological counterpart of the contrast effect-the tendency for a S's judgment of the intensity of a stimulus to be modified by the intensity of prior stimulation. When a tone was preceded by a softer tone, its AER amplitude increased; conversely, when a tone followed a louder tone, amplitude decreased. Irregular intervals between tones decreased the AER contrast effect, as did increasing the interval between tones. Further, significant correlations were found between individual scores on the AER contrast procedure and performance on a battery of psychophysical tasks.

Within certain intensity ranges, there is a tendency to judge a tone of a particular intensity as louder when it is preceded by a soft tone and as softer when it is preceded by a loud tone. The term "contrast effect" has been used to refer to this modification of the perception of stimulus intensity by the intensity of prior stimulation. The contrast effect has been demonstrated in experimental studies of "time error" (e.g., Holzman, 1954), "context effect" (e.g., Tempest et al; 1965), and "anchor effect" (e.g., Boardman et al, 1959). Contrast effects are one type of responsiveness to contextual stimulation. The effect of contextual stimuli on perceptual judgment may appear whether the context is spatial, temporal, or related to the S's instructional set. Individual differences in responsiveness to contextual stimuli have been studied

*The authors wish to express their thanks to James Henderson, Catherine King, and Nancy Dintiman for their assistance with this project. The authors also wish to express their appreciation to Dr. Richard Q. Bell for allowing us to use his thermal sensitivity apparatus. A schematic and specification of components for it is a valable from the Biomedical Enginecring and Instrument Branch, Room 3312, Building 13. NIH, Bethesda, Maryland 20014. When writing ask for Drawing 714010-1.

**Laboratory of Psychology. Nalional Institute of Mental Health, Public Health Scrvice. U.S. Department of Health, Education, and Welfare.

***Adult Psychiatry Branch, National Institute of Mental Health, Public Health Service, U.S. Department of Health, Education, and Welfare (now at Research Department, Agnews State Hospital, Agnews, Californii).

†National Heart Institute. National Institutes of Health, Public Health Service, U.S. Department of Health, Education, and Welfare.

††Adult Psychiatry Branch, National Institute of Mental Health, Public Health Service, U.S. Department of Health, Lducation, and Welfare. both in normal Ss (Gardner et al, 1959) and in patients with various abnormal psychological and biochemical states (Venables, 1964; Henkin \& Daly, 1968). Recent perceptual studies in our laboratory indicated that specific parameters of the evoked response are associated with individual differences in perceptual response tendencies. In the present study an evoked response procedure was developed to study contrast effects.

In planning this evoked response procedure's design, we relied on the following facts: (1) A tendency exists for AER amplitude to increase and for latency to decrease with increasing stimulus intensity (Davis \& Zerlin, 1966; Rapin et al, 1966). (2) Wide individual differences in the rate of increase in AER amplitude have been found (Davis et al, 1968; Rose \& Ruhm, 1966; McCandless \& Best, 1966). (3) Similar mathematical functions have been found to fit both psychophysical judgment and AER amplitude data (Rosner \& Goff, 1967; Beck \& Rosner, 1968; Keidel \& Spreng, 1965). (4) A relationship exists between an individual's tendency to augment or reduce the perceived intensity of a stimulus and his evoked response amplitude (Buchsbaum \& Silverman, 1968; Blacker et al, 1968; Spilker \& Callaway, 1969; Silverman et al, 1969).

On these bases, we expected that a tone would produce an AER of shorter latency and greater amplitude when preceded by a softer tone than when preceded by a louder tone. Part 1 of this paper describes the evoked response contrast procedure. and Part 2 describes the relationship between individual scores on the evoked response procedure and scores on a battery of related psychophysical tasks.

\section{PART 1}

Method

Subjects. Twenty paid normal volunteers, 10 men and 10 women, ranging in age from 18 to 22 , served as Ss for these experiments.

Evoked potential procedures. The S was

seated in a comfortable chair in a darkened sound-treated room (background noise level of $40 \mathrm{~dB}$ ) and presented with two series of tones. His only instructions were to remain still and relaxed with eyes closed. Four $1,000-\mathrm{Hz}$ tones of $42,50,54$, and $62 \mathrm{~dB}$ were presented $1 \mathrm{sec}$ apart on two different sequences through a 6-in. PM speaker $1 \mathrm{~m}$ directly in front of the S's head. The tones were $500 \mathrm{msec}$ long and had a trapezoidal envelope with rise and decay time of approximately $10 \mathrm{msec}$.

The EEG was obtained vertex $\left(C_{z}\right)$ to right ear with left ear ground. The amplified EEG was summed separately for each intensity by the Mnemotron CAT (Computer of Average Transients) for a 0.5-sec period; each AER represented 120 stimulus presentations. Grass silver disk electrodes were used; electrode resistance was generally between 8 and $12 \mathrm{~K}$ ohms. The input impedance of the Grass PS-5 amplifier used was 6 megohms. Thus, eve a variation of as much as $10 \mathrm{~K}$ ohms in electrode resistance would affect the measured output signal less than $0.5 \%$.

Two sequences of tones of the same four intensities were presented to each $S$. The first sequence of tones was $62,54,42$, and $50 \mathrm{~dB}$. This sequence of tones was presented 120 consecutive times (a total of 480 tones). After a 10-min rest, the second sequence of tones was presented. This sequence was $42,54,62$, and $50 \mathrm{~dB}$. The two stimulus presentation sequences are illustrated in Fig. 1a. Note that in the first sequence the tone of intensity $54 \mathrm{~dB}$ is always preceded by a tone of the highest intensity, and the tone of intensity $50 \mathrm{~dB}$ is always preceded by a tone of the lowest intensity. This format was reversed in the second sequence.

Latency and amplitude of the most stable evoked response components to the onset of a tone were measured. These were a negative wave peaking at $90-130 \mathrm{msec}$ $\left(\mathrm{N}_{1}\right)$ and a positive wave at $150-200 \mathrm{msec}$ $\left(\mathrm{P}_{2}\right)$. Peak-to-trough measurements were made from $P_{1}$ to $N_{1}$ (referred to here as $N_{1}$ ) and from $N_{1}$ to $P_{2}$ (referred to here as $P_{2}$ ). The amplitudes and the latencies of peaks $N_{1}$ and $P_{2}$ were measured for the evoked responses to the 50 - and $54-\mathrm{dB}$ tones. On Sequence I a larger amplitude and shorter latency AER was expected in response to the $50-\mathrm{dB}$ tone than to the 54-dB tone; on Sequence Il a larger amplitude and shorter latency AER was expected in response to the 54-dB tone 


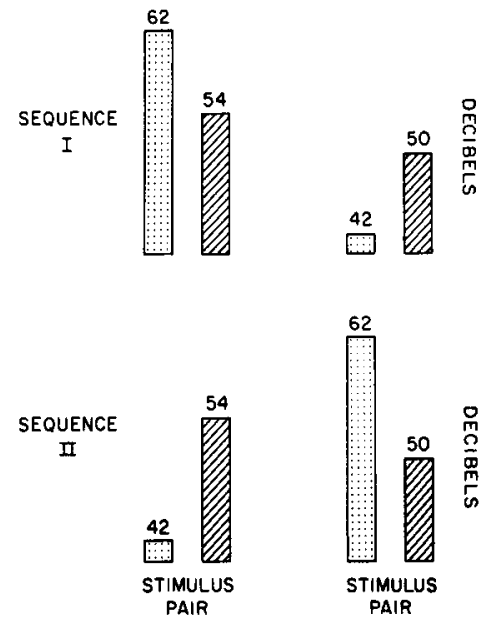

Fig. 1a. Sequences of tone presentations. Hatched bars represent tone intensities under study. Dotted bars are tones presented for contrast.

than to the 50-dB tone. An AER contrast measure was then calculated separately for the amplitude and latency of each peak in the following way: (1) The values for the two tones which we expected to be increased by contrast, the $50-\mathrm{dB}$ tone in Sequence $I$ and the $54-\mathrm{dB}$ tone in Sequence II, were summed. (2) The values for the two tones which we expected to be decreased by contrast, the $54-\mathrm{dB}$ tone in Sequence 1 and the $50-\mathrm{dB}$ tone in Sequence II, were summed. (3) The contrast values were computed by subtracting the (1) value from the (2) value. This value was then divided by four.

In addition to the main AER contrast experiment described above, four additional experiments were run in order to explore other parameters of evoked response contrast effects and to test for alternative explanations. In these experiments smaller groups of Ss were used.

Effect of interstimulus interval. The same sequence of tones was used but the interval between tones was changed. Three additional runs were carried out; the intertone interval was different on each run $(0.6,1.0$, and $2.0 \mathrm{sec})$. Eight Ss were tested.

Effect of irregular tone spacing. Again, the same sequence of tones was used, but in this experiment the intertone interval was randomly varied between $0.8,1.0$, and $1.2 \mathrm{sec}$ (see Fig. 1b). Six Ss were tested.

Effect of interpolated stimuli. The original stimulus pairs were maintained, 62.54 and 52.50 in the first series and 42.54 and 62.50 in the second. A tone selected at random was interposed between each pair, and the pairs were presented in random order. The interstimulus interval
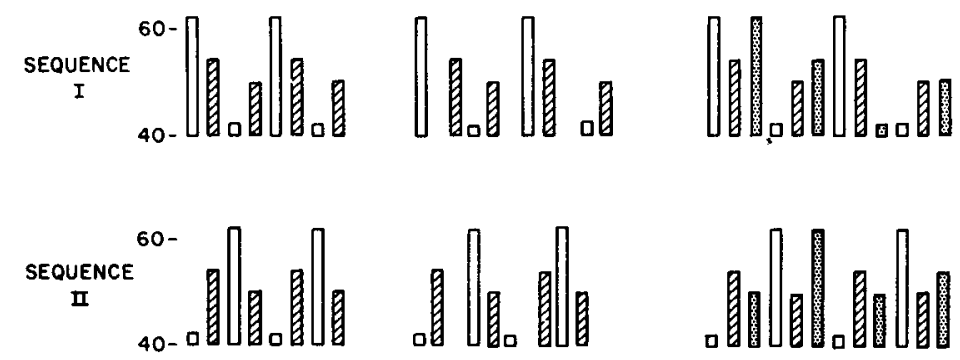

Fig. 1b. Sequences of tone presentations for irregular and interpolated series. Hatched bars represent tone intensities under study. Plain bars are tones presented for contrast. In the interpolated series, the dotted bars are the random interpolated tones.

remained fixed at $1 \mathrm{sec}$ (Fig. 1b). Ten Ss were tested.

Comparison with constant intensity tone presentation. The four intensities of tones were presented in randomized blocks of 10 tones of equal intensity; the interval between each block was $3 \mathrm{sec}$. Each intensity of tone was presented 120 times. Twenty Ss were tested.

Peak-to-trough measurements of AER were used rather than a measurement from a zero baseline obtained prior to stimulation, since we have found higher test-retest stability using peak-to-trough measures for auditory stimuli. In a group of 17 normal Ss, tested twice several weeks apart, peak-to-trough measurements $\left(\mathrm{N}_{1} \cdot \mathrm{P}_{2}\right)$ had a test-retest correlation of 0.82 , but baseline to peak $P_{2}$ or $N_{1}$ had test-retest values of approximately 0.40 .

\section{Results}

The auditory evoked responses of nearly all Ss tested showed the expected contrast effect. As predicted, the AER of the second tone of a pair usually had a longer latency and smaller amplitude when it was preceded by a louder tone than when it was preceded by a softer tone. Out of 20 Ss, 19 showed this effect for the amplitude of $P_{2}$ and 15 for the latency of peak $N_{1}$. In the first sequence, AER amplitude for the 50-dB tone was $1 \frac{1}{2}$ times greater than for the 54-dB tone. In the second sequence, AER amplitude for the $50-\mathrm{dB}$ tone was approximately half that of the 54-dB tone. Mean contrast values for both latencies and amplitudes of $N_{1}$ and $P_{2}$ were all significantly different from zero (t test, $p<.02$ for each mean).

A number of recent studies have indicated sex differences in various sensory perceptual parameters and in evoked response characteristics (Bell \& Darling, 1965; Buchsbaum \& Silverman, 1968; Duffy, 1962; Rodin et al, 1965; Wilson \& Zung, 1966). Broverman and his colleagues (1968) reviewed the literature on biochemical and neurophysiological correlates of perceptual processes and pointed out the serious limitations of studies that do not take sex differences into account; therefore, our data were analyzed for each sex separately. Males showed less contrast effect than did females for both the latency of peak $N_{1}$ and $\mathrm{P}_{2}$ (t test, $\left.\mathrm{p}<.05\right)$. On the evoked response amplitude contrast scores, females tended to show less contrast effect than did males $(.10>p>.05)$, although the difference was statistically not quite significant (see Table 1). Figure 2 shows typical examples of evoked response contrast effects. Table 2 shows mean amplitude measurements for peak $\mathrm{P}_{2}$.

Effect, of interstimulus interval. Increasing the time interval between tones decreased the effect of a loud or soft tone on subsequent auditory AER. Table 3 shows the data for the three time intervals studied. One-way analysis of variance for repeated measures showed significant change for latency contrast effect $(p<.02)$ and borderline significance $(.10>p>.05)$ for amplitude contrast. All six Ss tested on this procedure showed the effect for latency contrast; four Ss also showed the effect for amplitude contrast.

Effect of irregular tone spacing. If the time intervals between tones were randomly varied from 0.8 to $1.2 \mathrm{sec}$, the contrast effect of a loud or soft tone on the subsequent auditory AER was significantly decreased (by $t$ test, $\mathrm{p}<.01$ ). $\mathrm{N}_{1}$ amplitude contrast was decreased from

Table 1

Contrast Values on Peaks $N_{1}$ and $P_{2}$ of the Evoked Response Waveform

\begin{tabular}{cccccc}
\hline & \multicolumn{2}{c}{$\begin{array}{c}\text { Latency } \\
\text { (Milliseconds) }\end{array}$} & & \multicolumn{2}{c}{$\begin{array}{c}\text { Amplitude } \\
\text { (Microvolts) }\end{array}$} \\
\cline { 2 - 5 } \cline { 5 - 6 } & $\mathrm{N}_{1}$ & $\mathrm{P}_{2}$ & & $\mathrm{~N}_{1}$ & $\mathrm{P}_{2}$ \\
\hline$\delta$ & -11.0 & -4.1 & .20 & 0.85 \\
$q$ & -3.6 & -1.4 & .32 & 1.07 \\
\hline
\end{tabular}

Note-The larger the positive value, the greater the degree of contrast effect for amplitude measures; the greater the negative value, the greater the contrast effect for latency measures. 


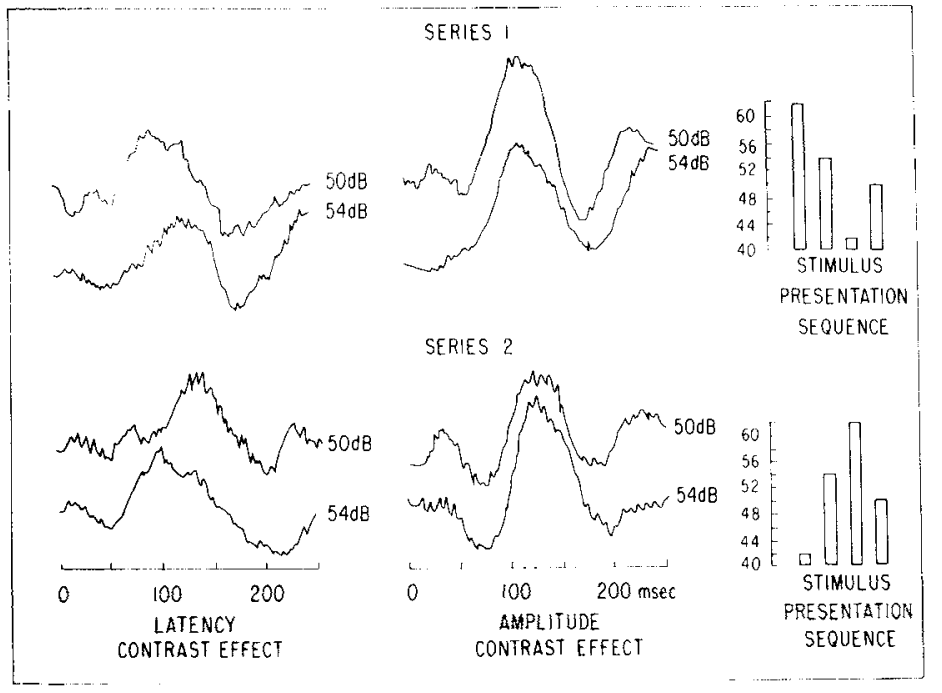

Fig. 2. Cortical evoked responses to 50 and $54 \mathrm{~dB}$ tones in two sequences of presentation, showing typical latency and amplitude contrast effects.

Table 2

Amplitude Peak $P_{2}$

\begin{tabular}{llllllll}
\hline & & \multicolumn{2}{c}{$\begin{array}{c}\text { Preceded } \\
\text { by Tone }\end{array}$} & Series 1 & $\begin{array}{c}\text { Preceded } \\
\text { by Tone }\end{array}$ & Series 2 & Preceded \\
by Tone & Series 3 \\
\hline \multirow{2}{*}{ Males } & $50 \mathrm{~dB}$ & Softer & $4.18 \pm .89$ & Louder & $1.79 \pm .45$ & Same Intensity & $3.58 \pm .60$ \\
& $54 \mathrm{~dB}$ & Louder & $2.53 \pm .26$ & Softer & $3.57 \pm .23$ & Same Intensity & $3.45 \pm .30$ \\
& $50 \mathrm{~dB}$ & Softer & $4.46 \pm 1.72$ & Louder & $2.15 \pm .23$ & Same Intensity & $4.05 \pm .35$ \\
& $54 \mathrm{~dB}$ & Louder & $2.62 \pm .33$ & Softer & $4.33 \pm .30$ & Same Intensity & $5.14 \pm .21$ \\
\hline
\end{tabular}

1.9 to 0.7 microV and $P_{2}$ contrast from 3.7 to 1.2 microV. All six Ss showed decreased latency contrast on peak $\mathrm{N}_{1}$.

Effect of interpolated stimuli. Introducing tones of randomly selected intensity between pairs of stimuli markedly decreased the contrast effect. Amplitude contrast was significantly decreased on peak $\mathrm{P}_{2}$ from 5.7 to 1.3 microV (by 1 test, $\mathrm{p}<.01$ ). Latency contrast was decreased in 8 out of $10 \mathrm{Ss}$ on $\mathrm{N}_{1}$, but the difference was of only borderline significance.

Comparison with constant-intensity tone presentation. In comparison with AER to tones presented in blocks of the same intensity, AER to tones in the contrast series had increased amplitudes when preceded by a softer tone and decreased amplitudes when preceded by a louder tone. Greater decreases in AER amplitude were seen when the test tones were preceded by a tone of greater intensity than amplitude increases when the test tones were preceded by a tone of lesse intensity.

\section{Discussion}

The results of these experiments with tone series suggest that a tone's intensity can influence the amplitude of the AER to the following tone and that there are individual differences in the extent of this effect. The AER technique may provide an excellent means for studying parameters that affect psychophysical judgments, as many parallels between psychophysical and AER results were found. As previously demonstrated in numerous psychophysical studies (e.g., Helson, 1967), increasing the length of time between stimuli decreased contrast effects.

Decreases in the AER contrast effect were also noted when the regularity of the sequence of stimulus presentations was reduced. Under these conditions Ss appeared to treat each tone independently and to minimize the contrast effect. The interval randomization may have increased the complexity of the Ss' sensory field, thereby heightening the difficulty in sustaining a coherent organization of the field.

The possibility that the AER contrast effect is the result of sensory end-organ Table 3

Effect of Interstimulus Interval on Evoked Response Anchoring

\begin{tabular}{|c|c|c|c|c|c|}
\hline & & \multicolumn{3}{|c|}{ Interstimulus Interval (in Seconds) } & \\
\hline \multicolumn{2}{|c|}{ Anchoring Values } & 0.6 & 1.0 & 2.0 & \\
\hline $\begin{array}{l}\text { Latency } \\
\text { (in Milliseconds) }\end{array}$ & $\begin{array}{l}\mathrm{N}_{1} \\
\mathrm{P}_{2}\end{array}$ & $\begin{array}{l}-16.5 \\
-11.1\end{array}$ & $\begin{array}{l}-4.2 \\
-2.8\end{array}$ & $\begin{array}{l}+1.3 \\
+4.0\end{array}$ & $\begin{array}{l}(p<.01)^{*} \\
(p<.01)\end{array}$ \\
\hline $\begin{array}{l}\text { Amplitude } \\
\text { (in Microvolts) }\end{array}$ & $\begin{array}{l}\mathrm{N}_{1} \\
\mathrm{P}_{2}\end{array}$ & $\begin{array}{l}+0.80 \\
+2.00\end{array}$ & $\begin{array}{l}+1.13 \\
+2.32\end{array}$ & $\begin{array}{r}+1.46 \\
+.85\end{array}$ & $\begin{array}{l}(.10>\mathrm{p}>.05) \\
(.10>\mathrm{p}>.05)\end{array}$ \\
\hline
\end{tabular}

* One-way analysis of variance. Signed numbers same as in Table 1. interpolated stimuli condition when the tone pairs were not disturbed.

Our observation that the AER contrast effect is greater when the test tone is preceded by a louder tone than when it is preceded by a softer tone was predicted by Tempest and Bryan (1966). Their work, using subjective relative loudness judgments (Tempest, McRobert, \& Bryan, 1965), shows comparable results for tones in the same intensity range as ours. Effects on tone AER consistent with ours have recently been reported by Butler (1968) in experiments with tone series of alternating intensities. In these experiments (especially Experiment 2), a 70-dB tone AER was preceded by $50-, 70$, and 90-dB "test stimuli"; the resulting AER amplitudes were 17,16 , and 14 microV, respectively. Thus, as in our experiments, a preceding soft tone increased AER amplitude and a preceding loud tone decreased it.

Interstimulus Interval (in Seconds) fatigue must be considered. The experiment utilizing interfering interpolated stimuli was undertaken to investigate this possibility. If some simple recovery from fatigue were involved, the tone immediately preceding the 50 - or $54-\mathrm{dB}$ tones would be responsible for the contrast effect, and a tone of random intensity preceding it should have no effect. In the interpolated series (Fig. 1b), the interpolated tones never separate the tone pairs being studied, but occur before each tone pair; yet the contrast effect was markedly diminished, thus mitigating strongly against end-organ fatigue as a source of the contrast effect. Additional evidence against the fatigue explanation is the at tenuation of the AER contrast effect seen in the irregular tone spacing experiment. Any fatigue effect would be unlikely to be altered by minor variations in the tone spacing so long as the mean interval between tone onset remained constant at $1 \mathrm{sec}$. However, the contrast effect was markedly diminished, again mitigating against end-organ fatigue as an important source of the contrast effect.

Another alternative explanation of the AER contrast effect is that we are observing changes caused by the superimposition of terminal portions of one AER on a subsequent one. Had this been the case, the contrast effect should not have been attenuated in the 


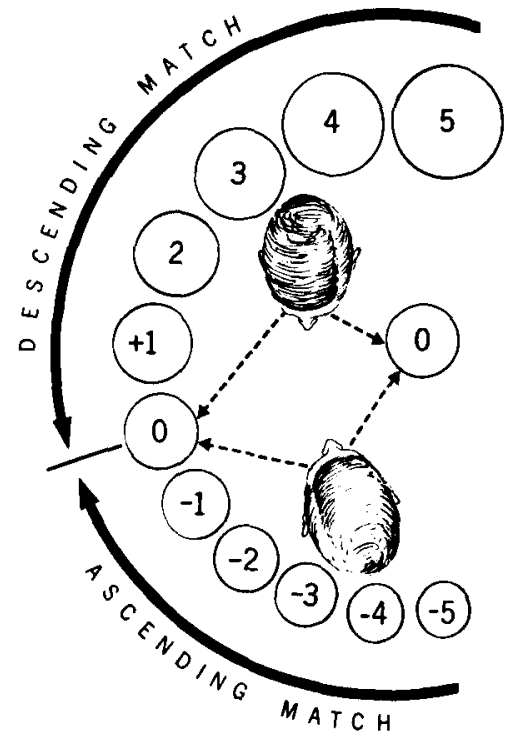

Fig. 3. Diagram depicting the size matching psychophysical task.

\section{PART 2}

Part 2 reports the application of the AER procedure to the study of psychophysical judgments. In previous investigations in our laboratory, a battery of tests has been employed to measure the extent to which perceptual judgments are influenced by irrelevant contextual cues of starting position and direction of stimulus change. We suspected that contrast effects would be involved in psychophysical judgments on these tasks. A schematic description of one of these tasks is presented in Fig. 3. The $S$ is asked to match the size of a standard disk to one of a variable series of disks On descending trials he begins with the largest disk. If the starting position has no effect on the S's performance, he matches the same size disk to the standard on ascending trials and on descending trials. Most Ss, however, are affected by the size of the stimulus that begins a variable series. The extent to which a $S$ is affected is operationally defined as the difference between his judgment score on ascending trials and his judgment score on descending trials.

\section{Method}

The same Ss who were tested on the AER contrast procedure were tested on the battery of psychophysical procedures. The testing was carried out in four or five sessions, which extended over a period of approximately 6 weeks. The sequence of testing was varicd with each $\mathrm{S}$. The Ss were not aware of the hypotheses of the study.

Anchoring measures (psychophysical). A battery of six tests was administered to each $S$ in a mixed order. On the first task the $S$ was required to match the size of a standard stimulus disk to a variable stimulus disk (visual kinesthetic); on Task 2 he matched the width of a standard stimulus bar to a variable stimulus bar (kinesthetic). The third and fourth tasks required the matching of the intensity of a standard tone or light stimulus to a variable stimulus (auditory No. 3 and visual No. 4). The auditory task is the alternate binaural loudness balance procedure. The fifth and sixth tasks were a two-flash fusion threshold procedure and a thermal judgment procedure.

On each task the $S$ was presented with a series of stimuli and asked to indicate the stimulus in the series which matched a standard stimulus. Half of the trials began with the variable stimulus set above the standard (e.g., larger, wider, more intense). The variable stimulus was then reduced in magnitude until the $S$ indicated that it matched the standard. These trials are referred to here as the descending (D) series. The other half of the trials began with the variable stimulus set below the standard (e.g., smaller, narrower, less intense). The variable stimulus was then increased in magnitude until the $S$ indicated that it matched the standard. These trials are referred to here as the ascending (A) series. Twelve trials were presented in the order DAAD, DAAD, DAAD.

Visual size estimation. The size estimation device used displays a bright disk on a dark background by rear screen projection (Silverman, 1964). By turning a crank with his right hand, the $S$ could increase or decrease the size of the disk. He was asked to change the size of the disk until it appeared to be the same size as the standard gray metal disk that he held in his left hand. Trials were begun with the variable disk width at $7 \mathrm{~cm}$ for ascending trials and at $3 \mathrm{~cm}$ for descending trials.

Kinesthetic size estimation. The apparatus used consisted of two 50-in.-long Lucite bars. One was of constant width, $1.5 \mathrm{in}$., and the other of variable width, from 1.0 to 2.5 in., graduated in 1/16-in. steps. The $\mathrm{S}$ was blindfolded and stood between the bars, which were mounted parallel and at a convenient height. Using his thumb and index finger to feel both bars simultaneously, the $S$ compared the widths, starting at the 1 -in. width for the ascending trials and at the 2.5-in. width for the descending trials. After each trial the $\mathrm{E}$ set the S's hands at the starting point for the next trial. This procedure is described in detail in the paper by Buchsbaum and Silverman (1968), with the modification that no interpolated stimulation condition was used.

Alternate binaural loudness balance. The $S$ was seated alone in an Industrial Acoustic Corporation 1204 sound chamber. Tones were generated by a
Beltone clinical audiometer and presented separately to the left and right ears of each $S$ through Telephonics TDH-39 earphones with MX-4l AR cushions. First, audiometric thresholds were determined in each ear at frequencies of $125-8,000 \mathrm{~Hz}$ by a method which has been described elsewhere (Hirsh, 1952; Henkin et al, 1967). Thresholds for each $S$ included in the study were normal and the same in both ears. For each trial an intermittent $1,000 \cdot \mathrm{Hz}$ standard tone was presented $40 \mathrm{~dB}$ above zero [International Standards Organization (ISO) hearing level] to one ear, alternating with the intermittent test tone presented to the opposite ear. The $S$ was instructed to report whether the test tone was louder than, softer than, or equal to the loudness of the standard tone. A new trial began as soon as the $\mathrm{S}$ indicated a match. The test tone started at $80 \mathrm{~dB}$ above zero (ISO hearing level) on descending trials and at zero (ISO hearing level) on ascending trials. The intensity was increased or decreased $5 \mathrm{~dB}$ after each presentation.

light intensity judgment. The $\mathrm{S}$ observed two circular lights, $4 \mathrm{~cm}$ in diam, $15 \mathrm{~cm}$ apart, and $1 \mathrm{~m}$ distant, mounted inside a black hood. The left light, the standard stimulus, was a $50-\mathrm{fc} 110-\mathrm{V}$ incandescent light source mounted inside a metal tube behind a circle of white milk glass. The right light, the variable light, was identically constructed. Its intensity was controlled by a variac, motor driven at $1 \mathrm{rpm}$. The lamp's intensity was measured by sampling the voltage output of two solar cells inside the lamp housing with a digital voltmeter. The intensity at which the standard was set and the intensity range of judgments made by the Ss were within a fairly narrow range; within this range the color temperature of the bulb was relatively stable.

At the beginning of each of the 12 trials the variable light was turned off. Then, with the variac set to either zero or maximum voltage, both the standard and the variable lights were turned on, and the motor controlling the brightness of the variable stimulus was started in the appropriate ascending or descending direction. When the $S$ judged that the light intensity of the variable matched the standard, he stopped the variable light from changing further by pushing a button; this stopped the motor with an instantaneous braking action. The intensity could not be readjusted by the $S$. After each trial, the $E$ recorded the digital volt reading, turned off both lights, and set the equipment for the next trial. The brightness of the lights did not require the $\mathrm{S}$ to be dark adapted. The task took 15 min.

The variable light was standardized with a Nems-Clark light meter; a polynomial, 
Table 4

Psychophysical Scores

\begin{tabular}{lcc}
\hline & Males & Females \\
\hline Light Intensity (lumens) & $-0.13^{*}$ & -0.10 \\
Kinesthetic Size (in.) & 0.17 & 0.32 \\
Two Flash (msec) & 3.16 & 0.23 \\
Sound Intensity (dB) & 12.50 & 8.60 \\
Thermal $\left({ }^{\circ} \mathrm{C}\right.$ ) & 2.30 & 4.00 \\
Visual Size (cm) & 0.26 & 0.27 \\
\hline
\end{tabular}

*The larger the positive value, the greater the degree of starting position effect.

fitted to the calibration curve, was used to transfer the raw voltage values into approximate lumen values.

Two-flash threshold. A Grass PS-2 photostimulator with Intensity Setting 1 was used to present two 10 -microsec flashes with a variable delay between them.

On a descending trial they were presented $150,130,110,100,90,80,70$, $68,66, \ldots \mathrm{msec}$ apart, and on an ascending trial the paired stimuli were presented in the order, 20, 30, 40, 42, 44, ... msec apart. For each pair of flashes the $S$ indicated whether he silw one or two flashes. On the ascending serics, a trial was terminated as soon as the $S$ indicated he saw two flashes after a sequence of one-flash responses. On the descending series the trial was terminated after a $S$ indicated he saw one flash after a sequence of two-flash responses. The flashes were presented through a $20-\mathrm{mm}$ translucent frosted glass window into a normally illuminated room.

Thermal judgment. The thermal device consisted of a thermoelectric junction which heated and cooled a small metal plate. The plate covered the $26 \times 12 \mathrm{~mm}$ thermoelectric junction which was mounted flush in the convex side of a 21-cm-diam plastic hemisphere. Aluminum fins within the hemisphere conducted heat when the junction was cooled.

A variable autotransformer altercd the primary voltage of two $115 / 6.3-\mathrm{V} 20-\mathrm{A}$ transformers through two relays, thus altering the current through the thermoelectric junction. Because of the high current involved, three other relays were used for interlock and control functions so that the current through the junction was turned off before it was reversed. A thermistor probe attached to the junction monitored temperature from $1^{\circ} \mathrm{C}$ to $55^{\circ} \mathrm{C}$. At the beginning of each trial the $S$ placed the palmar surface of his right index finger on the platform for $15 \mathrm{sec}$. and his skin temperature was measured at the end of this time. The $S$ then removed his finger, and the temperature of the plate wits changed by the $\mathrm{E}$ to $10^{\circ}$ higher for descending trials and $10^{\circ}$ lower for ascending trials. The $S$ was then told to replace his finger on the plate; the plate temperature was then either raised or lowered in the direction of his skin temperature at about $4^{\circ} \mathrm{C} / \mathrm{min}$, the rate being slightly slower as skin temperature was reached. The $S$ indicated verbally when he thought the platform became "cool" in the descending trials (falling temperature) and "warm" in the ascending trials (rising temperature). Skin temperatures and cold and warm points were recorded to the closest $0.1^{\circ} \mathrm{C}$.

\section{Results}

The Ss showed a tendency to be influenced by starting position in the series of intensity judgments. Ss judged a more intense stimulus as equal to the standard on descending trials; they judged a less intense stimulus as equal to the standard on ascending trials. This was observed on all tests in the battery except the light intensity test. Mean scores for the battery are shown in Table 4 . All positive mean scores were significantly different from zero (by $t$ test, $\mathrm{p}<.02$ ).

A composite score for the six psychophysical tests was computed by first normalizing Ss' scores on each task and then computing for each $S$ the mean of these normalized scores. This score correlated $0.44(p<.05)$ with the AER contrast score for amplitude of $\mathrm{P}_{2}$ when the data for both sexes were combined. The multiple correlation coefficient of all psychophysical contrast measures with AER contrast, as measured by the amplitude of peak $P_{2}$, was $0.89(p<.05)$.

Male $S$ s showed higher correlations between performances on the various psychophysical judgment tasks as well as between the judgment tasks and evoked response contrast measures. Psychophysical scores on the sound intensity procedure correlated -0.61 with the AER amplitude contrast measure for peak $\mathrm{N}_{1}$ and -0.52 for peak $P_{2}$. Scores on all other psychophysical tasks also negatively correlated with AER amplitude contrast scorcs, but only AER/2-llash and AER/visual size estimation were statistically significant $(r=0.54$ for both, $p<.05$, one-tailed test). Contrast scores on the light intensity procedure correlated significantly with the AER latency contrast measure for peak $\mathrm{N}_{1}(\mathrm{r}=0.62, \mathrm{p}<.05)^{1}$; aii other AER latency contrast psychophysical correlations were positive but nonsignificant. Male Ss' scores on all six psychophysical tasks were significantly correlated with each other. Visual size estination showed the highest correlation with other tasks: 0.770 with 2-flash, 0.631 with sound intensity, 0.522 with thermal, and 0.456 with kinesthetic size. The correlation matrix is shown in Table 5 .

Female Ss showed much lower corrclations between AER contrast measures and the psychophysical battery; intercorrelations between the tests in the battery also were lower. While their correlations were in the same direction as the male group for AER contrast/psychophysical scores, none of these correlations was statistically significant. On 13 out of 15 possible correlations between psychophysical tasks, the correlations were lower in females (sign test, $\mathrm{p}=0.004$ ).

\section{DISCUSSION}

The results of the first part of this investigation indicate that contrast effects are demonstrable on an evoked response procedure. Further, in Part 2 individual differences in the extent of the AER contrast effect were found to be correlated with individual differences in performance on a battery of psychophysical test procedures. Individuals who exhibited contrast or order effects strongly appeared to do so for several sensory modalities.

Females, as compared with males, performed less consistently on the various psychophysical tasks. Since the testing extended over a 6-week period, the lower correlations in the female group may reflect the effects of the menstrual cycle on sensory behavior. It has been shown that judgments on various psychophysical measures, including the auditory task employed in this study, are significantly affected by carbohydrate active steroids (Henkin \& Daly, 1968), which vary with time. This task is also altered in patients with various abnormalities on gonadal steroid production (Henkin, Buchsbaum, \& Silverman, 1967).

The context effects observed here may

Table 5

\begin{tabular}{|c|c|c|c|c|c|c|}
\hline & Light & K-Size & Two l lash & Sound & Thermal & V-Size \\
\hline Light & 1.000 & & & & & \\
\hline Kincsthetic Size & .112 & 1.000 & & & & \\
\hline Two l'lash & .216 & .543 & 1.000 & & & \\
\hline Sound & .225 & .125 & .346 & 1.000 & & \\
\hline Thermal & .211 & .347 & .147 & .550 & 1.000 & \\
\hline Visual Size & .081 & .456 & .770 & .631 & .522 & 1.000 \\
\hline ALR amp $N_{1}$ & -.170 & .060 & -.550 & -.520 & -.180 & -.510 \\
\hline $\mathrm{AI}: \mathrm{R} \quad \mathrm{P}_{2}$ & -.119 & $\cdots .389$ & .102 & -.610 & -.420 & -.410 \\
\hline
\end{tabular}


be viewed as reflecting the perceptual response disposition "leveling-sharpening" described by Holzman and Klein (1954). They postulated that individuals can be typed by their manner of arranging sequences of related stimuli. "Levelers" are individuals who "characteristically organize a field in a simple or diffuse manner.They rely heavily upon anchors ... to maintain an organization." Levelers also tend to minimize differences between stimuli and prefer the experience of sameness to that of difference. "Sharpeners," in contrast, have a "propensity to maximize stimulus differences, an attunement to small gradients of difference between figure and ground." Holzman (1954) found, as we did, that $\mathrm{Ss}$ responded similarly across visual, auditory, and kinesthetic sense modalities.

Minimizing stimulus differences might well be associated with minimal starting position scores or even overshooting the point of veridicality on the psychophysical bettery. Further, the reliance on the immediate context in the alternation between the standard stimulus and the variable comparison stimulus should also reduce the effect of the starting position. The parallels between various well known psychophysical effects and the AER results suggest that the AER technique may be valuable for studying parameters which affect psychophysical judgments.

\section{REFERENCES}

BECK, C., \& ROSNER, B. S. Magnitude scales and somatic evoked potentials to percutaneous electrical stimulation. Physiology \& Behavior, $1968,3,947-953$.

BELL, R. Q., \& DARLING, J. F. The prone head reaction in the human newborn: Relationships with sex and tactile sensitivity. Child Development, 1965, 36, 943-949.

BLACKER, K. H., JONES, R., STONE, G., \& PFEFFERBAUM, D. Chronic users of LSD: The "Acidheads." American Journal of Psychiatry, 1968, 125, 3, 97-107.

BOARDMAN, W. K., ALDRICK, R. C., REINER, M. D., \& GOLDSTONE, S. The effect of anchors upon apparent length. Journal of Genetic Psychology, 1959, 61, BI45-49.

BROVERMAN, D., KLAIBER, E. L. KOBAYASHI, Y., \& VOGEL, W. Roles of activation and inhibition in sex differences in cognitive abilities. Psychological Review, 1968 $75,23-50$.
BUCHSBAUM, M., \& SILVERMAN, J. Stimulus intensity control and the cortical evoked response. Psychosomatic Medicine, 1968, 30, 12-22.

BUTLER, R. A. Effect of changes in stimulus frequency and intensity on habituation of the human vertex potential. Journal of the Acoustical Society of America, 1968, 44, 945-950.

DAVIS, H., \& ZERLINE, S. Acoustic relations of the human vertex potential. Electroencephalography \& Clinical Neurophysiology, 1966, 21, 109-116.

DAVIS, H., BOWERS, C., \& HIRSH, S. Relations of the human vertex potential to acoustic input: Loudness and masking. Journal of the Acoustical Society of America, 1968, 43, $431-438$.

DUFFY, E. Activation and behavior. New York: Wiley, 1962.

GARDNER, R., HOLZMAN, P. S., KLEIN, G. S., LINTON, H., \& SPENCE, D. P. Cognitive control. Psychological Issues, 1959, I, Monograph 4.

HELSON, H. Adaptation-level theory. New York: Harper \& Row, 1964.

HENKIN, R. I., MCGLONE, R. E., DALY, R., \& BARTTER, F. C. Studies on audito:y thresholds in normal man and in patients with adrenal cortical insufficiency. Journal of Clinical Investigations, 1967, 46, 429-435.

HENKIN, R., BUCHSBAUM, M., \& SILVERMAN, J. Sensory abnormalities in patients with Turner's syndrome. The Physiologist, 1967, 10, 199.

HENKIN, R., \& DALY, R. Auditory detection and perception in normal man and in patients with adrenal cortical insufficiency: Effect of adrenal cortical steroids. Journal of Clinical Investigations, $1968,47,1269-1280$.

HIRSH, I. Measurement of hearing. New York: McGraw-Hill, 1952.

HOLZMAN, P. S. The relation of assimilation tendencies in visual, auditory and kinesthetic time-error to cognitive attitudes of leveling and sharpening. Journal of Personality, 1954, 22, 375-394.

HOLZMAN, P., \& KLEIN, G. S. Cognitive system-principles of leveling and sharpening: Individual differences in assimilation effects in visual time error. Journal of Psychology, 1954, 37, 105-122.

KEIDEL, W. D. \& \& SPRENG, M. Neurophysiological evidence for the Stevens power function in man. Journal of the Acoustical Society of America, 1965, 38, 191-195.

KENSHALO, D. R. Changes in the cool threshold associated with phases of the menstrual cycle. Journal of Applied Physiology, 1966, 21, 1031-1039.

MCCANDLESS, G. A., \& BEST, L. Summed evoked responses using pure tone stinuli. Journal of Speech \& Hearing Research, 1966 9, 266-272.
RAPIN, I., SCHIMMEL, H., TOURK, L. M., KRASNEGOR, N. A., \& POLLAK, C. Evoked responses to clicks and tones of varying intensity in waking adults. Electroencephalography \& Clinical Neurophysiology, 1966, 21, 335-344.

RODIN, E. A., GRISSELL, J. L., GUDOBBA, R. D., \& ZACHARY, G. Relationship of EEG background rhythms to photic evoked responses. Electroencephalography \& Clinical Neurophysiology, 1965, 19, 301-304.

ROSE, D. E., \& RUHN, H. B. Some characteristics of the peak latency and amplitude of the acoustically evoked response. Journal of Speech \& Hearing Research, 1966, $9,412-422$.

ROSNER, B. S., \& GOFF, W. R. Electrical responses of the nervous system and subjective scales of intensity. In D. W. Neff (Ed.), Contributions to sensory physiology. Vol. 2. Now York: Acaldemic Press, 1967. Pp. 169-221.

SILVERMAN, J. Scanning-control mechanism and "cognitive-filtering" in paranoid and non-paranoid schizophrenia. Journal of Consulting Psychology, 1964, 28, 385-393.

SILVERMAN, J., BUCHSBAUM, M., \& HENKIN, R. Stimulus sensitivity and stimulus intensity control. Perceptual \& Motor Skills, $1969,28,71-78$.

SPILKER, B., \& CALLAWAY, E. "A ugmenting" and "reducing" in averaged visual evoked responses to sine wave light. Psychophysiology, 1969, 6, 49-57.

TEMPEST, W., MCROBERT, H., \& BRYAN, M. E. The estimation of relative loudness. Paper B16, in D. E. Commins (Ed.), Proceedings of the Fifth International Congress on Acoustics. Liege: Thone. 1965.

TEMPEST, W., \& BRYAN, M. E. Objective audiometry. Journal of the Acoustical Society of America, 1966, 40, 914 .

VENABLES, P. $H$. Input dysfunction in schizophrenia. In B. A. Maher (Ed.), Personality research. New York: Acadenic Press, 1964.

VIERIING, J. S., \& ROCK, J. Variations in offactory sensitivity to Exultolide during the menstrual cycle. Journal of Applied Physiology, 1967, 22, 311-315.

WILSON, W. P., \& ZUNG, W. K. Attention, discrimination and arousal during sleep. Archives of General Psychiatry, 1966, 15 , 523-52.8.

WOODWORTH, R. S., \& SCHLOSBERG, H. Experimental psychology. (Rev. ed.) New York: Holt, Rinehart \& Winston, 1954.

NOTE

1. Since AER latency decreases with intensity, the AER latency contrast scores have the opposite sign from AER amplitude measures.

(Accepted for publication October 18, 1970.) 